Research Paper

\title{
CCR7 promote lymph node metastasis via regulating VEGF-C/D-R3 pathway in lung adenocarcinoma
}

\author{
Jie Yu\#, Shaolin Tao\#, Pingping Hu, Ruwen Wang, Chunshu Fang, Yi Xu, Di Qi, Zhuanqin Wei, Jingge \\ Zhang, Qunyou Tan ${ }^{凶}$ \\ Department of Thoracic Surgery, Institute of Surgery Research, Daping Hospital, Third Military Medical University, Chongqing 400042, P. R. China. \\ \#These authors contributed equally to this work. \\ $\square$ Corresponding author: Qunyou Tan, Department of Thoracic Surgery, Institute of Surgery Research, Daping Hospital, The Third Military Medical University, \\ Chongqing 400042, P. R. China. fax:+862368767988. tanqy001@163.com. \\ (C) Ivyspring International Publisher. This is an open access article distributed under the terms of the Creative Commons Attribution (CC BY-NC) license \\ (https://creativecommons.org/licenses/by-nc/4.0/). See http://ivyspring.com/terms for full terms and conditions.
}

Received: 2017.01.05; Accepted: 2017.04.01; Published: 2017.07.05

\begin{abstract}
Lymph node metastasis is still an important issue in metastatic process of lung adenocarcinoma. C-C chemokine receptor 7 (CCR7) has been proved to be closely associated with the metastasis of lung adenocarcinoma, and the mechanism is poorly understood. In order to investigate the relationship between CCR7 and lymph node metastasis in lung adenocarcinoma, and to explore the role of CCR7 in treating lung adenocarcinoma, 40 clinical specimens were collected to define the relationship between CCR7 and lymph node metastasis in lung adenocarcinoma by immunohistochemistry. The siRNA was used to suppress CCR7 expression in A549 cells. The scratch test, transwell test, qRT-PCR, western blot, flow cytometry and immunofluorescence were used to investigate the lymph node metastasis-related function of CCR7 in vitro. The athymic mice subcutaneous injection was used to research lung adenocarcinoma formation in vivo. Clinical case studies show that higher expression of CCR7 in lung adenocarcinoma tissues was associated with a higher lymph node metastasis. Inhibition of expression of CCR7 can reduce the migration and invasion and suppress the expression of VEGF-C, VEGF-D and VEGF-R3 in vitro and in vivo. Moreover, CCR7 silence also suppressed WNT and p-ERK pathways in vitro. All the results indicate that CCR7 can promote lymph node metastasis in lung adenocarcinoma by regulating VEGF-C/D-R3 pathway. Thus CCR7 is proposed to be a potential prediction for poor prognosis of lung adenocarcinoma, and a therapeutic target for lymph node metastasis.
\end{abstract}

Key words: CCR7, lung adenocarcinoma, lymph node metastasis, VEGF-C/D-R3

\section{Introduction}

Lung cancer is one of the most common lethal malignancies and lung adenocarcinoma accounts for more than $80 \%[1,2]$. Metastasis is the major factor associated with poor prognosis of lung adenocarcinoma, in which lymph node metastasis is an important way $[3,4]$. It is thus necessary to explore an optimal molecular target for suppressing the lymph node metastasis and improving the therapeutic ratio.

Chemokine receptor 7 (CCR7) is a G-protein -coupled receptor that belongs to $\mathrm{C}$ chemokine receptor family. It has high efficiency chemical driving effect on some human $\mathrm{T}$ cell lines and peripheral blood lymphocytes, suggesting a specific for lymphocytes. CCL19 and CCL21 are its specific ligands [5]. The large numbers of research revealed that CCR7 express highly in several kinds of cancer cell, and this phenomenon is associated with lymph node metastasis by lymphocyte trafficking and homing to lymph nodes during immune and inflammatory reactions [6-9]. High expression of CCR7 was detected in lung adenocarcinoma and its cancerous lymph nodes $[10,11]$. These results suggest that CCR7 may become a diagnostic and therapeutic target in the treatment of malignant tumor. But there 
is still no systematic research into the relationship between CCR7 and lymph node metastasis.

VEGF-C/D is one of the vascular endotheial growth factor family, is mainly involved in mediating lymphatic endothelial cell proliferation and differentiation [12]. VEGF-C/D has a strong specificity, and VEGF-R3, as the only receptor of VEGF-C/D, directly involved in lymphangiogenesis. Some studies show that the overexpression of VEGF-C, VEGF-D and VEGF-R3 is closely related to lymph node metastasis in several kinds of cancer [13-15].

Based on the above data we hypothesized that: CCR7 can be regulated via the VEGF-C/D-R3 pathway and promotes lymphatic metastasis of lung cancer. To assess the functional role of CCR7 in lung adenocarcinoma cells, we developed a lentivectormediated small interfering RNA (siRNA) approach to selectively downregulate the expression of CCR7 in lung adenocarcinoma A549 cells. The transwell experiment and scratch test shows that the invasion and migration ability was inhibited with the CCR7 silencing. The qRT-PCR and Western Blot technique confirmed the mRNA and protein level changes of VEGF-C, VEGF-D and VEGF-R3 were consistent with CCR7. Furthermore, the above phenomenon is further confirmed in vivo xenograft in nude mice. The research suggests that JNK, ERK and WNT pathways play an important role in helping cancer to spread, and may be a potential target for future new drugs [16-18]. In this study, immunofluorescence was used to observe the expression of JNK, ERK and WNT pathways, in order to further study the crosslinking method between CCR7 and VEGF-C/D-R3.

\section{Materials and Methods}

\section{Patients and Tissue Samples}

40 lung adenocarcinoma patients who had taken the operation treatment from Daping Hospital were selected in this study. All tumor and paratumor tissues were harvested within 30 minutes from complete resection. The tissue samples were obtained by surgical biopsy and processed through paraffinembedded by Pathology Daping Hospital and the immunohistochemistry was confirmed by BeiJing Cowin Biotech Co.

\section{Cell culture and reagents}

Normal epithelium, H23, Lewis-llc, A549 and H2066 in the experiment were all stable cultured in our laboratory. The cells were cultured in DMEM high glucose medium (GIBCO) with $10 \%$ of Australia fetal bovine serum (GIBCO) in an atmosphere of 5\% $\mathrm{CO}_{2}$ at $37^{\circ} \mathrm{C} .75 \mathrm{~cm}^{2}$ culture flasks were selected and all cell sample were harvested in a solution of trypsin-EDTA at the logarithmic growth phase (GIBCO).

Primers for qRT-PCR were purchased from Invitrogen (Table 1). The following antibodies in Western Blot tests were purchased from Abcom. Rabbit monoclonal to CCR7 (ab32527), Rabbit polyclonal to VEGFC (ab9546), Mouse monoclonal to VEGFD (ab38687), Rat monoclonal to VEGF Receptor 3 (ab91124). RNAi oligonucleotides for silencing human CCR7 was designed by literature and BLAST. The siRNA synthesis, vector assembly and lentivector packaging were accomplished by Shanghai Gene Chem Co. Ltd.

\section{Immunohistochemistry analysis}

40 patients' tumor and paratumor tissues were collected and processed for immunohistochemistry using rabbit anti-CCR7. Immunoreactivity was detected using the Poly Horseradish Peroxidase Detection System and 3, 30-diaminobenzidine (CWbio) following the manufacturer's instructions.

\section{Cell transfection}

Table 1. Primer sequences and annealing temperatures for quantitative RT-PCR

\begin{tabular}{llll}
\hline Gene name (accession no) & Primer sequences & $\begin{array}{l}\text { Primer } \\
\text { Tm }\end{array}$ & $\begin{array}{l}\text { Product } \\
\text { size(bp) }\end{array}$ \\
\hline$\beta$-actin (NM_001101) & $\begin{array}{l}\text { Forward 5'-AGCGAGCATCCCCCAAAGTT-3' } \\
\text { Reverse 5'-GGGCACGAAGGCTCATCATT-3' } \\
\text { CCR7(NM_001838.2) }\end{array}$ & 70 & 138 \\
& $\begin{array}{l}\text { Forward 5'-GGCCAGGTGTTCAAAGG-3' } \\
\text { Reverse 5'-CAAGGCGAGAAAGTTATTGC-3' }\end{array}$ & 70 & 156 \\
VEGF-C(NM_005429.2) & $\begin{array}{l}\text { Forward } \\
\text { 5'-ATTTACATGATGCTGCCATCAGTC-3' }^{\prime}\end{array}$ & 71 & 178 \\
& $\begin{array}{l}\text { Reverse } \\
5^{\prime} \text {-GGCAATAAAGCAATGGAGGAAGG-3' }\end{array}$ & & \\
VEGF-D(NM_004469.2) & $\begin{array}{l}\text { Forward 5'-AGGTTTATTTGCATGTGCC-3' } \\
\text { Reverse 5'-AGAGCAGGTCTTGATGTGTC-3' }\end{array}$ & 65 & 174 \\
VEGF-R3(NM_053652.1) & $\begin{array}{l}\text { Forward 5'-GTGGGTGGGTAGTGAGGAGA-3' } \\
\text { Reverse 5'-AGGTCATCTTCGTCGTCCC-3' }\end{array}$ & 71 & 166 \\
LYVE-1(NM_006691.3) & $\begin{array}{l}\text { Forward 5'-TGGAAAATGGAGGGCTAGTG-3' } \\
\text { Reverse 5'-ATTCATTTCTCTAATATGGCAACC-3' }\end{array}$ & 68 & 139 \\
\hline
\end{tabular}

The transfection system was constituted by lentivector dilution, polybrene and cell in logarithmic growth phase. The optimal titre of virus (MOI=30) was measured according to the transfection experiment. The flow cytometry was used to separate the cell the GFP expression level were between 10 to $10^{4}$ units after getting stable and highly express GFP A549 cells.

\section{Flow cytometry analysis}

Approximately $5 \times 10^{4}$ cells after transduction were seeded in 6-well culture plates and incubated 
in complete medium to $80-90 \%$ confluence. The cells were harvested, washed with ice-cold PBS twice, and fixed with DMEM. The flow cytometry was used to separate the cell the GFP expression level were between 10 to $10^{4}$ units with FACS Calibur flow cytometer (BD Biosciences) after getting stable and highly express GFP A549 cell.

\section{Tumor xenograft model}

6-week-old male nudes were selected (Experimental Animal Center of Daping Hospital). The suspension of A549 cells $\left(2 \times 10^{7} / \mathrm{ml}\right)$ was injected subcutaneously into the left axillary of each mouse. Mice were randomized for 5 per group (N: normal A549 cell line, S: CCR7-siRNA cell line, E: empty plasmid transfected A549 cell line) after tumors formed on 7 day postimplantation. Within 3 weeks the injection site skin changes and local reaction were observed regularly. Upon termination, each mouse was weighted and tumors were harvested for Western blot analysis and quantitative RT-PCR.

\section{The scratch test and transwell test}

3 groups of cells in logarithmic growth phase were seeded in 6-well cell culture plate. A trace on the surface of cells in culture was draw with a pipette tip, the scratches "healing" case was observed under phase contrast microscope after culturing with serum-free medium for 24 hours and 48 hours. Scratch marks width and the number of cells within the distribution were measured. The experiment was repeated thrice.

The paved matrigel transwell chamber were placed in 24-well plates. Cells in logarithmic growth phase $(70 \%-80 \%$ in integration of state) were made into cell suspension $\left(3.0 \times 10^{5} / \mathrm{ml}\right)$ and plated $0.2 \mathrm{ml}$ $\left(0.6 \times 10^{5}\right)$ per well into transwell upper chamber. Then removed the transwell chamber after $24 \mathrm{~h}$ culture. The inner surfaces of cells were erased using a cotton swab dipped in serum-free medium. Membrane was immersed in $95 \%$ ethanol for $10 \mathrm{~min}$ and stained by crystal violet. Ordinary optical microscope was chosen to observe cells penetrate the membrane of the lower chamber, counting five high power field and averaging analysis. The experiment was repeated thrice.

\section{Quantitative reverse}

\section{transcriptase-polymerase chain reaction}

Total RNA was extracted by the RNAiso plus (Invitrogen Co), cDNA was transcribed from mRNA with Prime Script RT-PCR Kit and Oligo dT Primer (Invitrogen Co). The mRNA level of CCR7, VEGF-R3, VEGF-C, VEGF-D were measured by Real-time quantitative PCR Thermal Cycler Dice Real Time System was used to amplification react the cDNA. The
qRT-PCR kit was provided by Invitrogen. All values were normalised to an endogenous $\beta$-actin control. Each mRNA was determined thrice.

\section{Western blot analysis}

Protein lysates were subjected to electrophoresis on a $4 \%$ SDS-PAGE and proteins were electrotransferred to polyvinylidene fluoride membranes. Membranes were incubated with 5\% non-fat dry milk in TBS and probed with anti-CCR7, anti-VEGF-C, anti-VEGF-D, anti-VEGF-R3 and anti-LYVE-1 in TBST (0.1\% Tween 20 in TBS). Horseradish peroxidase-conjugated anti-rabbit (or mouse) IgG (Sigma) was used for detection of immunoreactive proteins by chemiluminescence (Western Blot Chemiluminescence Reagent Plus). All Western blot assays were repeated 3 times.

\section{Immunofluorescence}

Three groups of cells were implanted into 6-well plates $\left(1 \times 10^{4} \quad\right.$ per well). Did $10 \%$ paraformaldehyde-fixed tissues, $10 \%$ goat serum, $1 \%$ Triton treatment to increase cell membrane permeability after cell morphology return to normal. After Using a rabbit anti-human ERK, WNT, JNK antibodies incubated overnight at $4{ }^{\circ} \mathrm{C}, 37{ }^{\circ} \mathrm{C}$ respectively, red fluorescence-labeled goat anti-rabbit secondary antibody incubated for 30 minutes in the dark and DAPI labeled nuclei dark for 15 minutes, the red, green and blue fluorescent were observed using fluorescence microscopy. Each Immunofluorescence assay was repeated 3 times.

\section{Statistical analysis}

The statistical results of the experiment were expressed in the form of the mean \pm standard deviation. Chi-square test was used for comparing the difference between the two groups, Chi-square test between any two groups was used for comparing the difference between several groups. The statistical software in experiment was GraphPad prism 5. $P$ values less than 0.05 were considered statistically significant.

\section{Results}

\section{The high expression of CCR7 is positively correlated with lymph node metastasis}

Clinical specimens'information were detailed records (Table 2). The average age was 51.63 years (38-73), the sex ratio was male: female 22: 18 . The patients were divided into lymph node metastasis group and the group without lymph node metastasis $(21 / 19)$ according to the test results of lymph node pathology. There was no significant difference in age and gender between the two groups $(P>0.05)$. 
Immunohistochemical staining was used for detecting CCR7 expression level. The results showed that there was significant difference in CCR7 expression level (Figure 1, Table 3). The patients were divided into CCR7 high expression group and CCR7 low expression group (24/16) according to the expression level of CCR7. There was no significant difference in age and gender between the two groups $(P>0.05)$. The Chi square test was used to comprehensive analyze the lymph node metastasis and the expression level of CCR7. The results showed that the high expression of CCR7 positive correlate to lymph node metastasis $(P<0.01$, Table 3$)$.

Table 2. Clinical specimens'information

\begin{tabular}{llll}
\hline Factor & Value & $\mathrm{N}$ & $\%$ \\
\hline Total Patients & $\mathrm{N}$ & 40 & 100 \\
Patient Sex & Female & 18 & 45 \\
& Male & 22 & 55 \\
Age at Trial Start & Mean(range) & $51.63(38-73)$ & - \\
(years) & & & \\
Lymph node biopsy & Lymph node metastasis(-) & 19 & 47.5 \\
& Lymph node metastasis(+) & 21 & 52.5 \\
CCR7 expression level & High & 24 & 60 \\
& Low & 16 & 40 \\
\hline
\end{tabular}

Table 3. Lymph node biopsy

\begin{tabular}{lllll}
\hline & & $\begin{array}{l}\text { Lymph node } \\
\text { metastasis(-) }\end{array}$ & $\begin{array}{l}\text { Lymph node } \\
\text { metastasis(+) }\end{array}$ & all \\
\hline CCR7 & High & 5 & 19 & 24 \\
expression & Low & 14 & 2 & 16 \\
level & all & 19 & 21 & 40 \\
& $\mathbf{K}^{2}$ & $<0.001$ & & \\
& Relevance $>0.999$ & & \\
\hline
\end{tabular}

\section{The effects of CCR7 siRNA on the expression of CCR7}

The A549 cell was chosen for the follow-up experiments because of the high CCR7 protein expression level (Figure 2A). The transfection of target cells by lentivector was successful, and the MOI was selected in 30 (Figure 2C). 3 stably cell lines were constructed: CCR7-siRNA A549 cells, empty plasmid A549 cells and untransfected normal A549 cells. The Western Blot test show that CCR7-siRNA can significantly reduce the expression level of CCR7 $(P<0.05$; Figure 2D, E). In comparison, no significant difference on protein level was found between A549 with empty plasmid and untransfected normal A549.
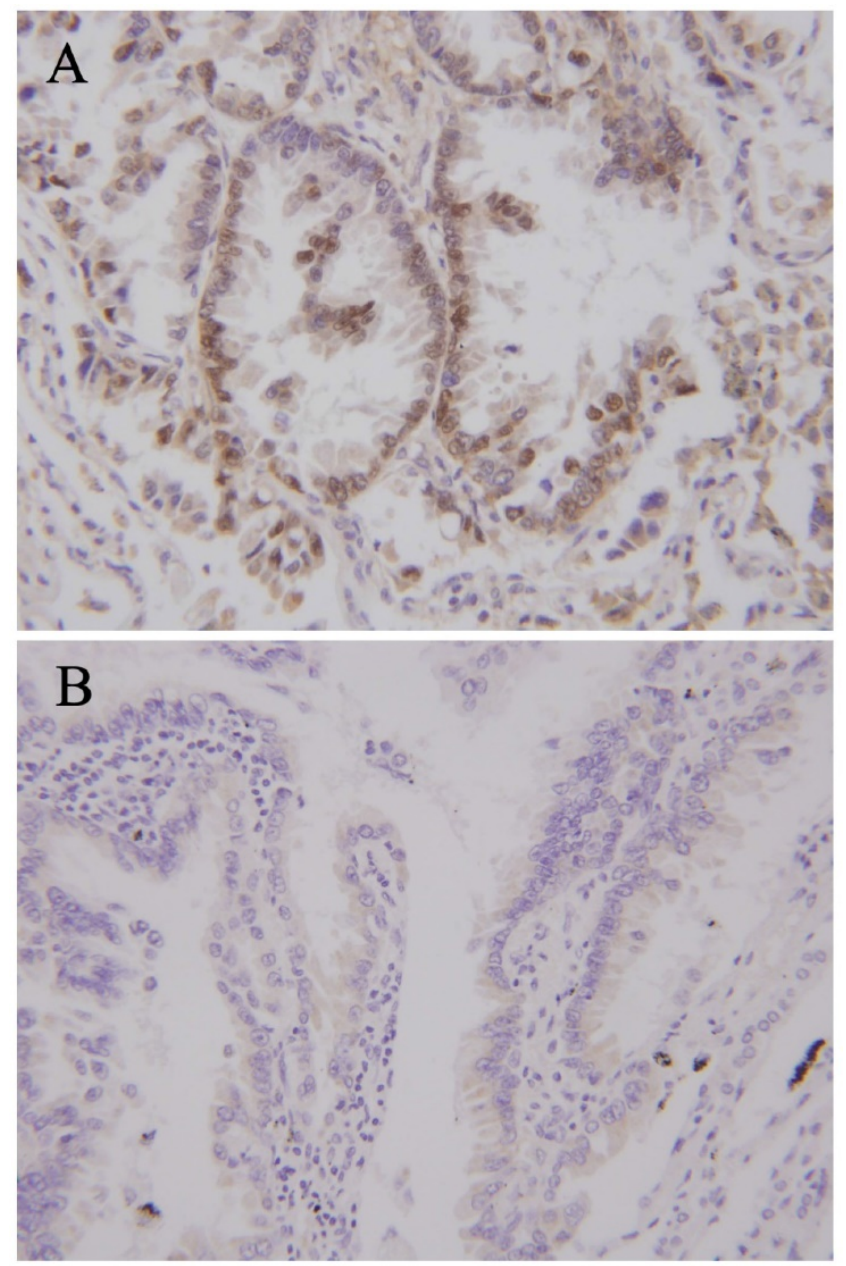

Figure 1. CCR7 expression levels in Lung adenocarcinoma. (A) Lung adenocarcinoma with high expression of CCR7. (B) Lung adenocarcinoma with low expression of CCR7.

\section{The effects of CCR7 siRNA on the biological behavior of A549 cells}

The scratch test was chosen to test the migration ability of three groups of A549 cell. After serum free culture for $24 \mathrm{~h}$ and $48 \mathrm{~h}$, different degrees of healing were observed. $S$ group with low expression level of CCR7 had poorer healing ability than $\mathrm{E}$ and $\mathrm{N}$ group with highly expression level of CCR7 $(P<0.05$; Figure 3A, B). Transwell experiments were used for the study of the invasion ability of A549 cell. After culture for $24 \mathrm{~h}$, we observed that three groups of cells were visible through the membrane into the lower chamber. The cell number of group $S$ was far less than group $\mathrm{E}$ and $\mathrm{N}(P<0.05$; Figure $3 \mathrm{C}, \mathrm{D})$. 


\section{The effects of CCR7 inhibition on the xenograft tumor}

A xenograft experiment was designed to investigate the function of CCR7 siRNA in vivo, and normal A549 cell line, CCR7-siRNA cell line, empty plasmid transfected A549 cell line and nude mice were selected. Mice bearing subcutaneous tumors were successfully constructed on the designed position. Those nude mice were put to death after 1 month. Tumor, peritumoral and lymph node tissue were taken out for paraffin section, HE staining and observation under a microscope. The tumor size of $S$
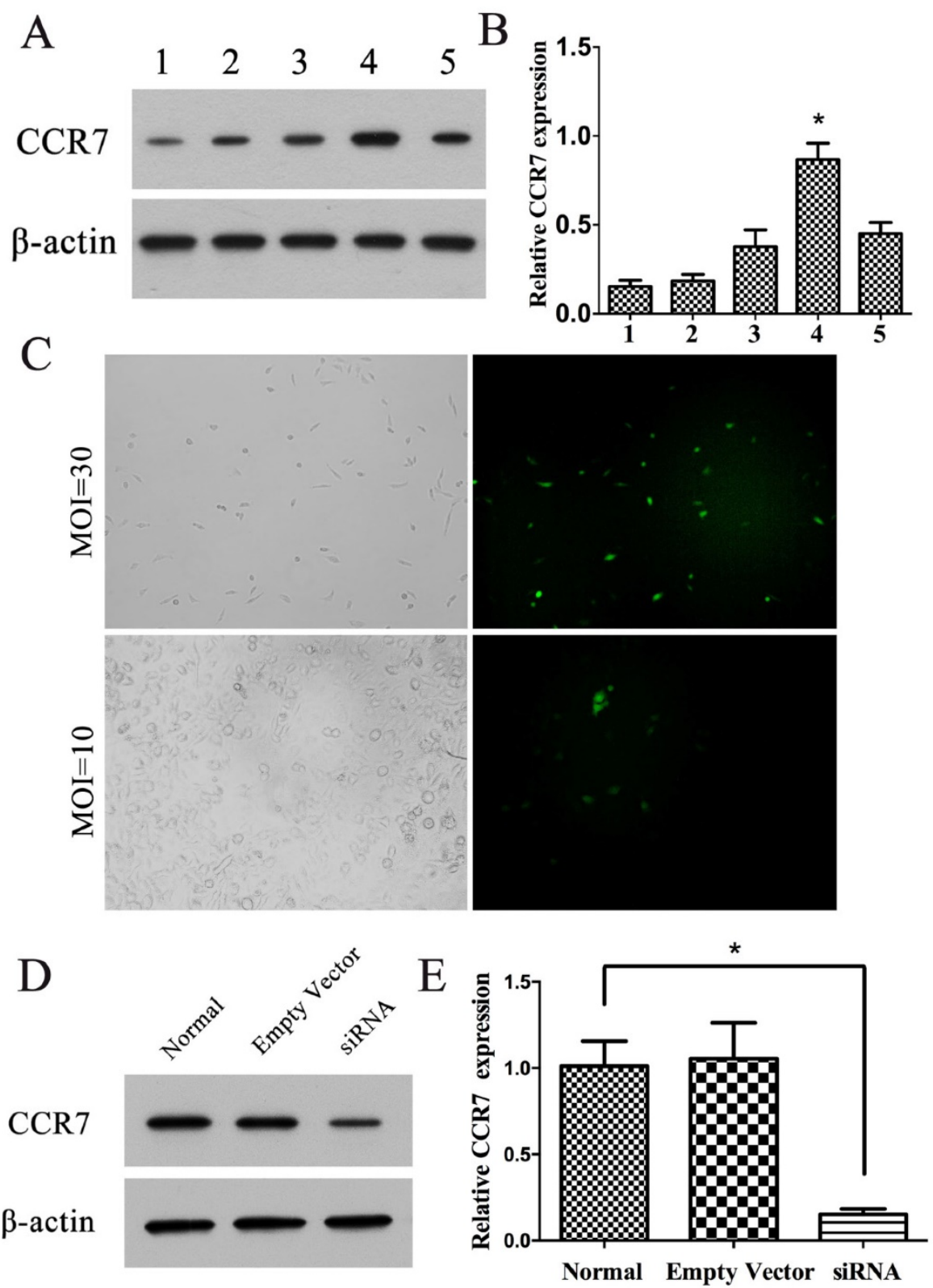

Figure 2. Construction of cell line with CCR7 stably silenced. (A, B) Western blot was performed to detect the expression ofCCR7 in normal epithelium, $\mathrm{H} 23$, Lewis-llc, A549 and $\mathrm{H} 2066$ cells. 1, normal epithelium; 2, $\mathrm{H} 23 ; 3$, Lewis-llc; 4, A549; 5, H2066. (C) A549 cells was transfected with CCR7-siRNA lentivector, and MTT assays were performed to determine the proliferation in A549 cells. $(D, E)$ Western blot was performed to detect the expression of CCR7 in cell line with CCR7 stably silenced.Data represent the mean \pm S.D. from three independent experiments. group was less than $\mathrm{N}$ and $\mathrm{E}$ group, and there was statistically significant $(P<0.05$; Figure 4$)$.

For the investigating of the function of CCR7 siRNA, the mRNA level of CCR7, VEGF-C, VEGF-D and VEGF-R3 in tumor tissue and paratumor tissue were measured by qRT-PCR. Simultaneously, the mRNA level of LYVE-1 was tested as the specific lymphatic markers. The analysis showed that CCR7, VEGF-C, VEGF-D and VEGF-R3 mRNA levels were significantly inhabited in the CCR7-siRNA cell line group. LYVE-1 expression level was also decrease $(P<0.05$; Figure $4 \mathrm{C}, \mathrm{D})$.

\section{The effects of CCR7 inhibition on VEGF-C/D-R3 axes in vitro}

For further validating the relationship between CCR7 and tumor lymphatic metastasis, the investigation in vitro was also carried out. The protein level of CCR7, VEGF-C, VEGF-D and VEGF-R3 in each group of A549 cell were measured by Western Blot. The analysis showed that CCR7, VEGF-C, VEGF-D and VEGF-R3 protein levels were significantly inhabited in the CCR7-siRNA cell line group. But no difference was found between empty plasmid transfected A549 cell line group and normal A549 cell line group $(P<0.05$; Figure 5 A-D). The results showed that CCR7 can inhibit the expression of VEGF-C/D-R3 axes.

Immunofluorescence was used for preliminary testing ERK, WNT and JNK expression levels. The results showed that ERK, WNT and JNK were all detected. The expression level of WNT and ERK had been upregulated in $S$ group comparing to $\mathrm{N}$ and $\mathrm{E}$ group $(P<0.05)$. However, we observed no difference in JNK (Figure 5E, F). These data indicated that CCR7 may affect the proliferation and metastasis potential of lung adenocarcinoma cells by altering ERK and WNT protein expression. 

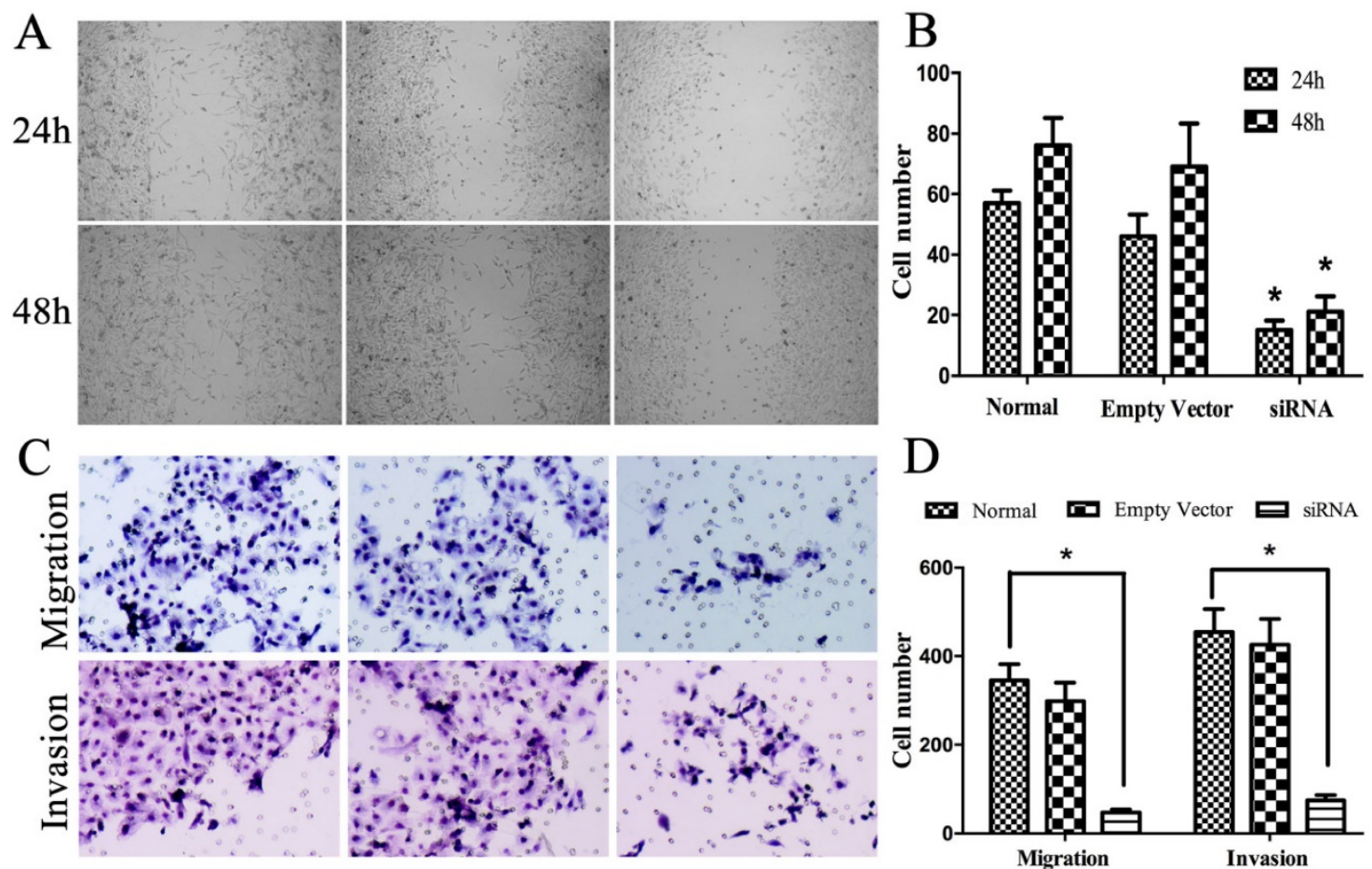

Figure 3. Effect of CCR7 on cell migration and invasion. (A, B) cell migration was measured by a scratch wound assay in vitro. (C, D). Transwell assays were performed to investigate the migratory and invasive ability in A549 cells with CCR7 stably silenced. $* P<0.05$
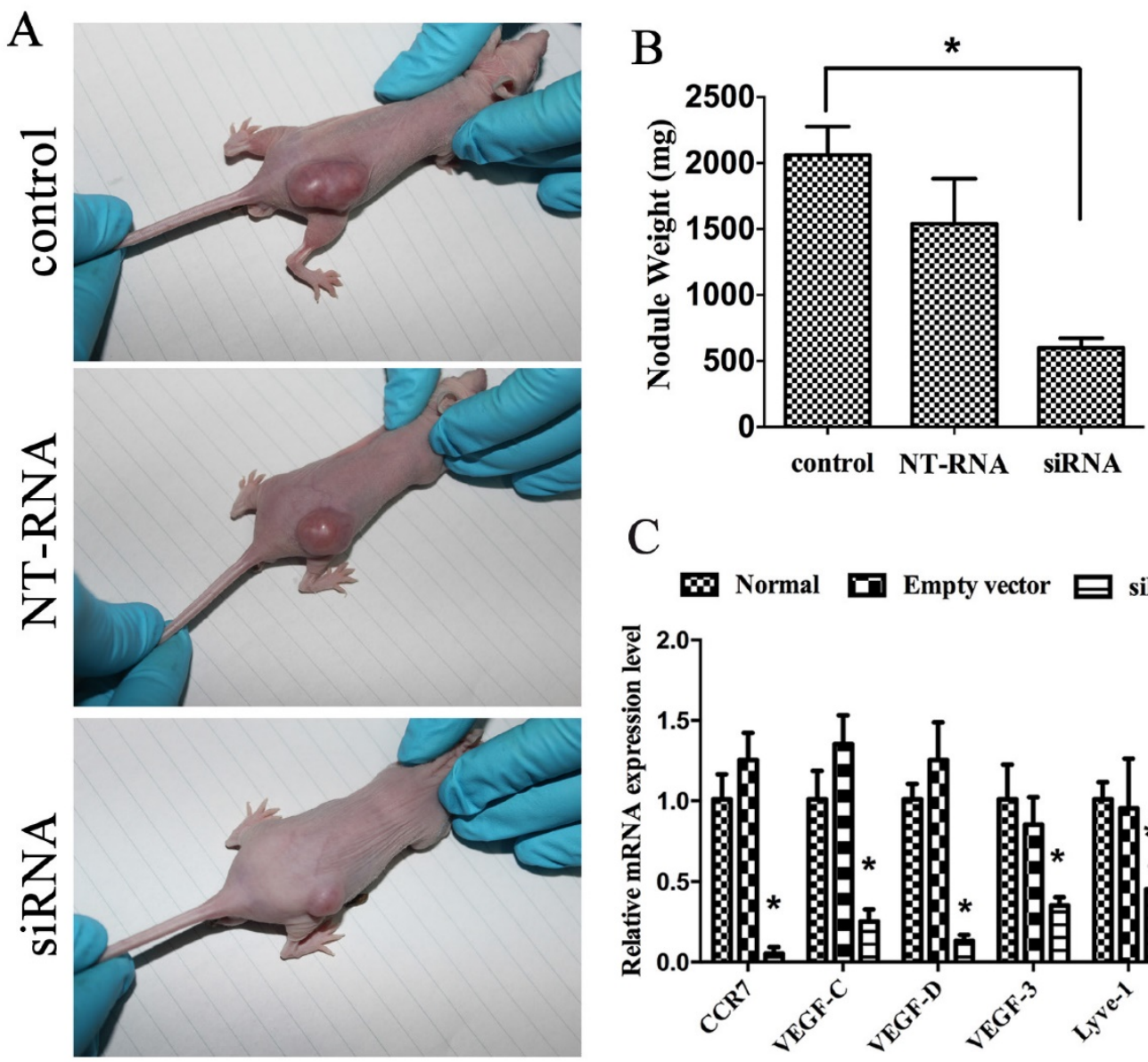

C

Dormal $\square$ Empty vector $\boxminus$ siRNA

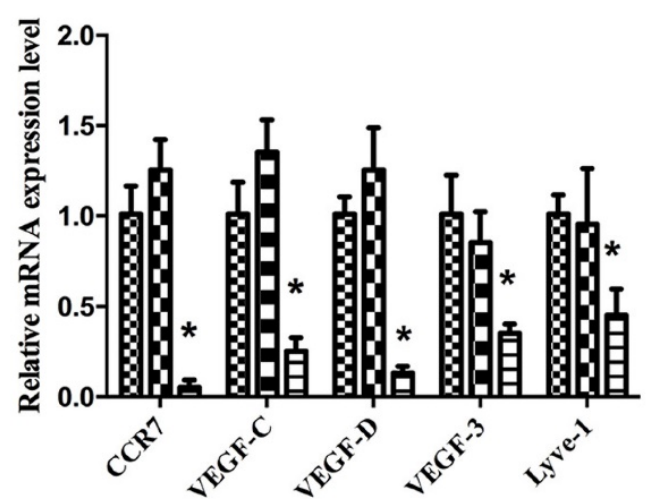

Figure 4. The effect of CCR7 on tumorigenesis in vivo. (A) CCR7-siRNA lentivector was transfected into A549 cells, which were injected in male athymic mice, respectively. (B) Tumor weights were calculated after injection 8 weeks. Bars indicate S.D. (C) qRT-PCR was performed to detect the expression of CCR7, VEGF-C, VEGF-D, VEGF-R3 and LYVE-1 in tumor nodule. $\beta$-actin was used as an internal control. $* P<0.05$. 


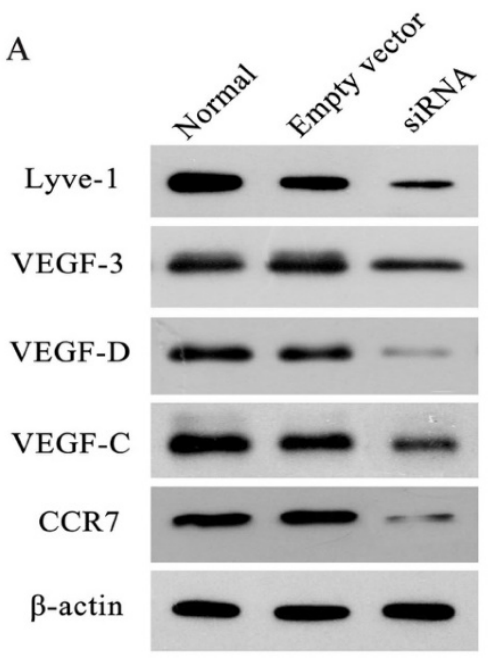

B

W Normal E Empty vector $\square$ siRNA

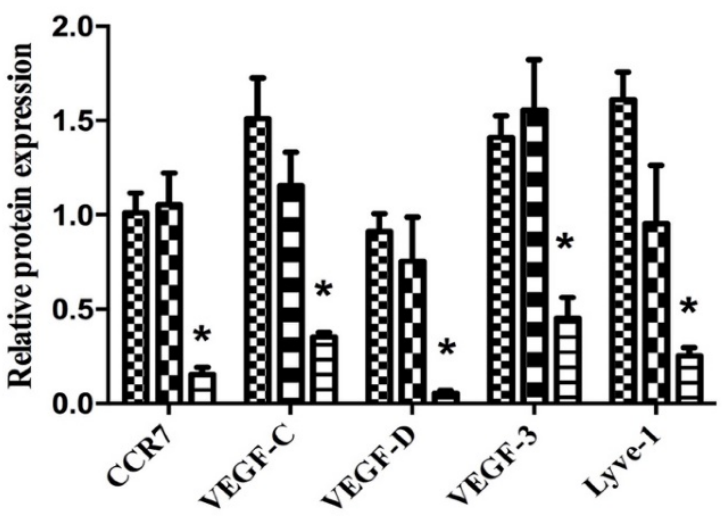

C
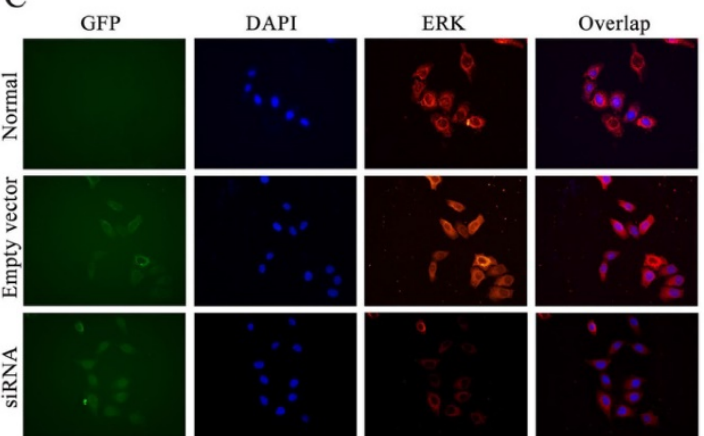

D
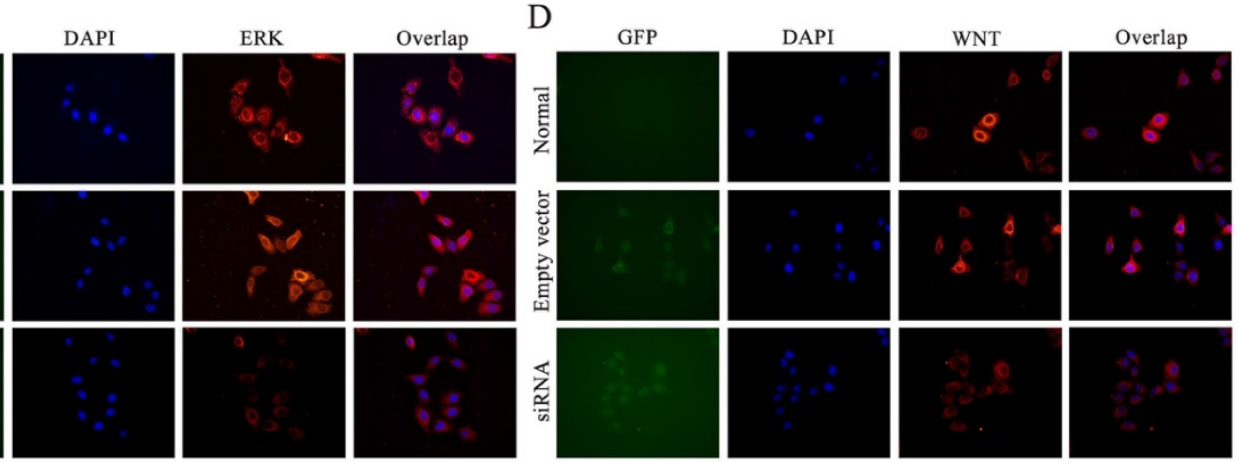

E GFP
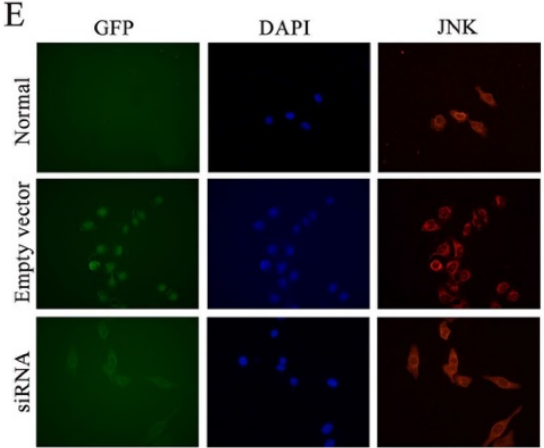

$\mathrm{F}$

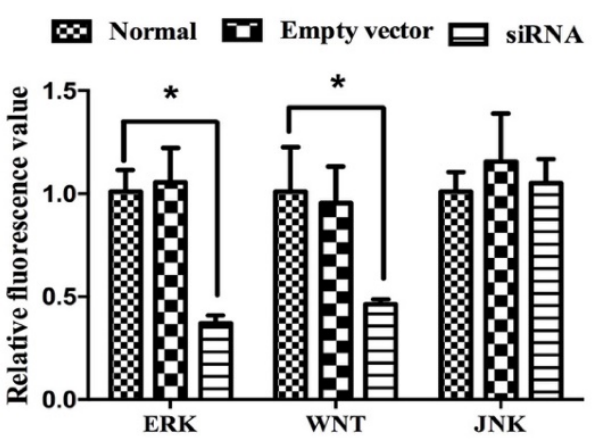

Figure 5. The effect of CCR7 on the expression of VEGF-C, VEGF-D, VEGF-R3 and LYVE-1 in vitro. (A, B) CCR7-siRNA lentivector was transfected into A549 cells, and Western blot was performed to detect the expression of CCR7, VEGF-C, VEGF-D, VEGF-R3 and LYVE-1 in A549 cells. (C-F) Immunofluorescence assays was performed to detect the expression of CCR7, VEGF-C, VEGF-D, VEGF-R3 and LYVE-1 in A549 cells. $* P<0.05$.

\section{Discussion}

Lymph node metastasis is one of the main ways of lung cancer metastasis, and also one of the main course of bad prognosis [19-21]. Our study found that CCR7 was expressed in a variety of lung adenocarcinoma cells. The high expression level was closely related to the occurrence of lymph node metastasis. We performed lentivector-mediated RNA interference against CCR7 expression to further confirm this feature of CCR7. The VEGF-C/D-R3 axis was found highly expressed in many kinds of malignancies and had been performed a promoting factor of lymph node metastasis in lung adenocarcinoma. By CCR7 silencing, we demonstrated that CCR7 canpromote lymph node metastasis in lung cancer by regulating VEGF-C/D-R3 pathway.

Lymph node metastasis is an important means assess prognosis in the clinical treatment of lung cancer. Clinical studies have confirmed that lymph node metastasis of lung cancer mostly occurs progressively [22-26]. Therefore, the occurrence and extent of lymph node metastasis is usually verified by lymph node stand-by biopsy. The result of biopsy is used for further lymph node dissection, and assessing the prognosis of patients [27-30]. But the promotion 
mechanism of lung adenocarcinoma cells promotes lymphangiogenesis and lymph node metastasis is still unclear. From recent study, we find that there must be a unique and comprehensive mechanism in lymph node metastasis comparing to metastasize. This is the first systematic study of the relation of CCR7 and lymph node metastasis and the possible mechanisms between them. Our results suggest that CCR7-VEGFC/D-VEGF-R3 axis is present in lung adenocarcinoma. By the inhibition of CCR7, the follow molecular can also reduce expressing, and the risk of lymph node metastasis can decrease along with it. Furthermore, WNT and ERK can participate the signal transduction. Notably, our result shows that CCR7 may also involve in regulating tumor cell growth. But the specific mechanism remains to be studied. We cannot rule out other mechanisms that CCR7 mediate lymphangiogenesis mechanism such as affecting the distribution some chemotactic factors.

According to our conclusion, the lung adenocarcinoma patients with high risk of lymph node metastasis can be advance screened by detecting CCR7 level. The lymph node biopsy and dissection in the following surgery should be taken seriously enough, the treatment options should also be appropriate adjust after surgery. The gene therapy of lung cancer is a hotspot in recent years. The key and difficult point of the research is the selection of molecular target [31-35]. Our study provides a possible answer to this question. CCR7 might become a new molecular target for treating lung adenocarcinoma according to its high levels of expression in tumor and paratumor tissue and high correlation to the lymph node metastasis. Current research proved that RNAi targeting of VEGF-C and VEGF-D can be an effective therapeutic strategy for lung adenocarcinoma. Combined with our research, the joint silence of CCR7 and VEGF-C/D may get better outcomes.

In summary, our studies show that CCR7 can inhibit proliferation and metastasis of lung adenocarcinoma by regulating the expression level of VEGF-C/D-R3 axes, WNT and ERK partially, which have laid us a theoretical basis for further understanding the pathogenesis of lung adenocarcinoma and conducting diagnosis and treatment.

\section{Acknowledgements}

This work was supported by grants from the National Natural Science Foundation of China (No. 81172239), the Natural Science Foundation of Chongqing, China (No. cstc2015jcyjA10073, No. cstc2015 jcyjBX0037), and the Research Foundation of the Third Military Medical University (No. 2007XG60).

\section{Competing Interests}

The authors declare that they have no competing interests.

\section{References}

1. Siegel R, Naishadham D and Jemal A. Cancer statistics, 2012. CA Cancer J Clin 2012; 62: 10-29.

2. Oser MG, Niederst MJ, Sequist LV, et al. Transformation from non-small-cell lung cancer to small-cell lung cancer: molecular drivers and cells of origin. Lancet Oncol. 2015, 6(4):e165-172.

3. Zhao X, Zhu G, Chen H, et al. Efficacy of icotinib versus traditional chemotherapy as first-line treatment for preventing brain metastasis from advanced lung adenocarcinoma in patients with epidermal growth factor receptor-sensitive mutation. J Cancer Res Ther. 2014, 10 Suppl:C155-159.

4. Coussa-Koniski ML, Maalouf PA, Raad NE, et al. Scrotal wall metastasis from a primary lung adenocarcinoma. Respir Med Case Rep. 2015, 15:77-79.

5. Cai W, Tao J, Zhang $X$, et al. Contribution of homeostatic chemokines CCL19 and CCL21 and their receptor CCR7 to coronary artery disease. ArteriosclerThrombVasc Biol. 2014 Sep;34(9):1933-1941.

6. Cheng S, Han L, Guo J, et al. The essential roles of CCR7 in epithelial-to-mesenchymal transition induced by hypoxia in epithelial ovarian carcinomas. Tumour Biol. 2014, 35(12):12293-12298.

7. Tutunea-Fatan E, Majumder M, Xin X, et al. The role of CCL21/CCR7 chemokine axis in breast cancer-induced lymphangiogenesis. Mol Cancer. 2015, 14:35.

8. Chen J, Cui YU, Liu L, et al. CCR7 as a predictive biomarker associated with computed tomography for the diagnosis of lymph node metastasis in bladder carcinoma. Oncol Lett. 2016, 11(1):735-740.

9. Peng C, Zhou K, An S, et al. The effect of CCL19/CCR7 on the proliferation and migration of cell in prostate cancer. Tumour Biol. 2015, 36(1):329-335.

10. Itakura M, Terashima Y, Shingyoji M, et al. High CC chemokine receptor 7 expression improves postoperative prognosis of lung adenocarcinoma patients. Br J Cancer. 2013, 109(5):1100-1108.

11. Zhang Q, Sun L, Yin L, et al. CCL19/CCR7 upregulates heparanase via specificity protein-1 (Sp1) to promote invasion of cell in lung cancer. Tumour Biol. 2013, 34(5):2703-2708.

12. Feng $\mathrm{Y}, \mathrm{Wang} \mathrm{W}, \mathrm{Hu}$, et al. Expression of VEGF-C and VEGF-D as significant markers for assessment of lymphangiogenesis and lymph node metastasis in nonsmall cell lung cancer. Anat Rec (Hoboken) 2010; 293: 802-812.

13. Tao S, Yu J, Xu Y, et al. PC4 induces lymphangiogenesis dependent VEGF-C/VEGF-D/VEGF-R3 axis activation in lung adenocarcinoma. Am J Cancer Res. 2015 May 15;5(6):1878-1889.

14. Maekawa S, Iwasaki A, Shirakusa T, et al. Correlation between lymph node metastasis and the expression of VEGF-C, VEGF-D and VEGF-R3 in T1 lung adenocarcinoma. Anticancer Res. 2007, 27(6A):3735-3741.

15. Bo C, Xiaopeng D, Chuanliang P, et al. Expression of vascular endothelial growth factors $C$ and $D$ correlates with lymphangiogenesis and lymph node metastasis in lung adenocarcinoma. ThoracCardiovasc Surg. 2009, 57(5):291-294.

16. Hwang JH, Joo JC, Kim DJ, et al. Cordycepin promotes apoptosis by modulating the ERK-JNK signaling pathway via DUSP5 in renal cancer cells. Am J Cancer Res. 2016, 6(8):1758-1771.

17. $\mathrm{Xu} \mathrm{WD,} \mathrm{Wang} \mathrm{J,} \mathrm{Yuan} \mathrm{TL,} \mathrm{et} \mathrm{al.} \mathrm{Interactions} \mathrm{between} \mathrm{canonical} \mathrm{Wnt}$ signaling pathway and MAPK pathway regulate differentiation, maturation and function of dendritic cells. Cell Immunol. 2016, 310:170-177.

18. Rey C, Faustin B, Mahouche I, et al. The MAP3K ZAK, a novel modulator of ERK-dependent migration, is upregulated in colorectal cancer. Oncogene. 2016, 35(24):3190-3200.

19. Ye B, Cheng M, Li W, et al. Predictive factors for lymph node metastasis in clinical stage IA lung adenocarcinoma. Ann Thorac Surg. 2014, 98(1):217-223.

20. Liu H, Ye YK, Li GM, et al. Diagnosis of lymph node micrometastasis at the $\mathrm{pN}_{\mathrm{N}}$ stage of lung adenocarcinoma using a combination of markers. Genet Mol Res. 2014, 13(3):5594-5600.

21. Morales-Oyarvide V, Mino-Kenudson M. High-grade lung adenocarcinomas with micropapillary and/or solid patterns: a review. CurrOpinPulm Med. 2014, 20(4):317-323.

22. Xue $\mathrm{XY}, \mathrm{Zhou} \mathrm{M}, \mathrm{Fu} \mathrm{WF}$, et al. Colonic metastasis from primary lung adenocarcinoma: case report and review of the literature. Med Oncol. 2012, 29(2):644-647.

23. Cao Y, Zhu LZ, Jiang MJ, et al. Clinical impacts of a micropapillary pattern in lung adenocarcinoma: a review. Onco Targets Ther. 2015, 9:149-158.

24. Harris JE Jr, Shin J, Lee B, et al. A murine xenograft model of spontaneous metastases of human lung adenocarcinoma. J Surg Res. 2011, 171(1):e75-79.

25. Zaric B, Stojsic V, Kovacevic $\mathrm{T}$, et al. Clinical characteristics, tumor, node, metastasis status, and mutation rate in domain of epidermal growth factor receptor gene in serbian patients with lung adenocarcinoma. J ThoracOncol. 2014, 9(9):1406-1410.

26. Kang DY, Lee S. Lymphatic vessel invasion and lymph node metastasis in patients with clinical stage I non-small cell lung cancer. ThoracCardiovasc Surg. 2014, 62(6):521-524. 
27. Kirita K, Ishii G, Matsuwaki R, et al. Identification of biological properties of intralymphatic tumor related to the development of lymph node metastasis in lung adenocarcinoma. PLoS One. 2013, 8(12):e83537.

28. Huang $\mathrm{HC}$, Hang JF, Wu MH, et al. Lung adenocarcinoma with ipsilateral breast metastasis: a simple coincidence? J ThoracOncol. 2013, 8(7):974-979.

29. Neri S, Ishii G, Taira $T$, et al. Recruitment of podoplanin positive cancer-associated fibroblasts in metastatic lymph nodes predicts poor prognosis in pathological N2 stage III lung adenocarcinoma. Ann SurgOncol. 2012, 19(12):3953-3962.

30. Tsutani $\mathrm{Y}$, Miyata $\mathrm{Y}, \mathrm{Nakayama} \mathrm{H}$, et al. Sublobar resection for lung adenocarcinoma meeting node-negative criteria on preoperative imaging. Ann Thorac Surg. 2014, 97(5):1701-1707.

31. Zhu B, Yang JR, Fu XP, et al. Anti-tumor effects of gene therapy with GALV membrane fusion glycoprotein in lung adenocarcinoma. Cell BiochemBiophys. 2014, 69(3):577-582.

32. Kim HK, Lee HY, Choi YL, et al. Assessment of intratumoral heterogeneity of oncogenic driver mutations in surgically-resected lung adenocarcinoma: implications of percutaneous biopsy-based molecular assay for target-directed therapy. Anticancer Res. 2014, 34(2):707-714.

33. Sun Z, Wang L, Eckloff BW, et al. Conserved recurrent gene mutations correlate with pathway deregulation and clinical outcomes of lung adenocarcinoma in never-smokers. BMC Med Genomics. 2014, 7:32.

34. Shibata MA, Shibata E, Morimoto J, et al. Therapy with siRNA for Vegf-c but not for Vegf-d suppresses wide-spectrum organ metastasis in an immunocompetent xenograft model of metastatic mammary cancer. Anticancer Res. 2013, 33(10):4237-4247.

35. Wang $\mathrm{Z}, \mathrm{Wu} \mathrm{XL}, \mathrm{Wang} \mathrm{X}$, et al. The biophysical property of A549 cells transferred by VEGF-D. Scanning. 2014, 36(2):202-208. 